\title{
Sperm parameters on Iberian red deer: Electroejaculation and post-mortem collection
}

\author{
A.F. Martínez ${ }^{\text {a }}$,F. Martínez-Pastor b,c,*, M. Álvarez a , M.R. Fernández-Santos ${ }^{\text {b,c }}$, \\ M.C. Esteso ${ }^{\mathrm{b}, \mathrm{c}}$, P. de Paz ${ }^{\mathrm{d}}$, J.J. Garde ${ }^{\mathrm{b}, \mathrm{c}}$, L. Anel $^{\mathrm{a}}$ \\ a Animal Reproduction and Obstetrics, University of León, 24071 León, Spain \\ ${ }^{\mathrm{b}}$ Biology of Reproduction Group, National Wildlife Research Institute (IREC) (UCLM-CSIC-JCCM), 02071 Albacete, Spain \\ ${ }^{\mathrm{c}}$ Institute for Regional Development (IDR), Section of Cynegetics and Cattle Resources, UCLM, 02071 Albacete, Spain \\ ${ }^{\mathrm{d}}$ Molecular Biology, University of León, 24071 León, Spain
}

Received 14 February 2008; received in revised form 2 April 2008; accepted 4 April 2008

\begin{abstract}
Artificial reproductive technologies (ART) for cervids have improved, but a need remains for the collection of basic data. We studied two models of sperm collection in Iberian red deer, post-mortem (PM) in a wild population (179 samples) and by electroejaculation (EE) in a farmed population (37 samples), recording: testicular and epididymal weight, testicular diameter, sperm quantity, $\mathrm{pH}$ and osmolality and spermatozoa quality (motility by CASA, abnormal forms, cytoplasmic droplets, viability and acrosomal status). We tested the relationship of these parameters with stag age and compared the two models (PM and EE; medians showed). Genitalia parameters were linearly related to stag age (testicular diameter: $31.5-50.5 \mathrm{~mm}$ for $2-9$ years). Total number of spermatozoa collected were PM: $2.5 \times 10^{9}$ and EE: $3.6 \times 10^{9}(P>0.05)$, increasing with age only for PM. We found a positive relationship between testicular size and spermatozoa collected for PM. Osmolality and pH were PM: 6.28 and $378 \mathrm{mOsm} / \mathrm{kg}$; EE: 7.63 and $309 \mathrm{mOsm} / \mathrm{kg}(P<0.05)$. The $\mathrm{pH}$ increased with age only for EE. Percentage of motile spermatozoa was similar for PM and EE, but motility quality was lower for PM. Abnormal forms, proximal and distal droplets were lower for EE (22\%, $1.3 \%, 1.5 \%$ vs. PM: $23 \%, 4.3 \%, 83 \%)$. Viability was similar (74\%) and intact acrosomes were higher for EE (97\% vs. 89\%). Both PM and EE Q3 samples could be used for germplasm banking. This study contributes data for a better understanding of red deer spermatology and for the development of ART in cervids.
\end{abstract}

(C) 2008 Published by Elsevier Inc.

Keywords: Red deer; Epididymal spermatozoa; Electroejaculation; Sperm evaluation; Testicular growth

\section{Introduction}

The use of artificial reproductive techniques (ART) on wild ungulates has increased considerably during the last years, not only with conservationist purposes [1-4],

Q2 * Corresponding author at: Ciencia y Tecnología Agroforestal y Genética (ETSIA), Universidad de Castilla-La Mancha, Av. España s/ n, 02071 Albacete, Spain. Tel.: +34 967599 200x2581; fax: +34967594269. but also because several of them have become the focus of a quickly developing farming business for producing venison, velvet and trophies. Being an important business in several countries [5-7], electroejaculation (EE), estrous synchronization, artificial insemination and embryo transfer have been investigated in several cervid species [5,7-9], and the red deer has received most of the attention of farmers and researchers [10]. Moreover, due to the increased need of management programs for hunting reserves and taking advantage of the availability of samples during the hunting season, 
the post-mortem (PM) collection of spermatozoa has arisen as an alternative to other methods. Indeed, using semen from naturally dead or poached males is considered as a very good option for conservation programs $[2,11]$.

However, there is still a lack of data regarding several basic aspects of semen collection in cervids. In this article, we present data from Iberian red deer (Cervus elaphus hispanicus) collected from 1998 to 2003. During this period, we studied two models of sperm collection in this species: post-mortem harvesting from hunted free living stags and electroejaculation of farmed deer. This study deals with semen quality, genitalia morphometry and the effect of stag age on these parameters. To our knowledge, there are no previous studies on red deer presenting this kind of reproductive data and using this approach.

Electroejaculation is the preferred method for semen collection in this species, having been in use for more than 35 years [12,13]. This method allows the collection of high quality semen without noticeable differences from semen collected by natural service [6], but it requires restraint and sedation or anesthesia [7]. In fact, electroejaculated spermatozoa has produced offspring both after either laparoscopic-intrauterine or cervical insemination $[1,5,6,10]$. The artificial vagina has also being successfully used for obtaining ejaculates of good quality $[14,15]$, but complications (stag training and personnel risks) have limited its use.

Recovery of epididymal spermatozoa has received much less attention. Nevertheless, the number of studies on this topic have recently increased, due to an interest in obtaining doses from dead valuable individuals in farms, and because of its potential use in wildlife conservation programs and for the hunting business [16-18]. Electroejaculation is generally a less convenient option for wild animals, because of the troubles associated with its use. Although epididymal spermatozoa differ from ejaculated ones, this kind of samples have been successfully cryopreserved and used for artificial insemination or in vitro fertilization [19-26].

With this study we aimed at contributing to the current knowledge on the reproductive biology of red deer with a triple approach. First, presenting anatomical data we have obtained from wild (hunted) and farmed animals, and studying the predictive value of anatomical data (testicular size) on the sperm quantitative parameters; second, comparing quantitative and qualitative data from spermatozoa collected from the cauda epididymis (wild, post-mortem) and by electroejaculation (farmed); and third, testing the effect of stag age on the aforementioned data. We present the results of the two models (post-mortem and electroejaculated) together, to highlight the peculiarities of each kind of sample with respect to the other, which was not evident in previous studies. It is important to keep in mind that the two collection methods are closely bound with the rearing conditions of the animals. Therefore, rather than considering the pair post-mortem/electroejaculation, it is more adequate to define both groups as wild/post-mortem and farmed/electroejaculation. We have worked with the Iberian subspecies of red deer (C. elaphus hispanicus) which has not been extensively studied despite its importance in the economy and culture of many regions in the Iberian Peninsula [10].

\section{Materials and methods}

\subsection{Animals}

Samples were obtained during the beginning of the breeding season (rut), which in the Iberian Peninsula spans from early September to mid October [18,27]. Ejaculates were obtained from 18 Iberian red deer stags (C. elaphus hispanicus, Helzheimer 1909) during five consecutive years (1999-2003). Animals ranged 1.57.5 years of age and weighed $147.5[142.2-178.8] \mathrm{kg}$. They were housed in a half-freedom system at facilities of the University of Castilla-La Mancha (Albacete, Spain), and they were maintained under natural day length conditions $\left(38^{\circ} 57^{\prime} \mathrm{N}\right)$. During the experiment they lived in a meadow of $6500 \mathrm{~m}^{2}$ composed of Festuca arundinacea (52.4\%), Dactylis glomerata (28.6\%), Medicago sativa (14.3\%) and Trifolium repens (4.8\%). Fodder was based on barley, alfalfa and oats, and animals had ad libitum access to cereal straw and water. Animal handling was performed in accordance with the Spanish Animal Protection Regulation, RD223/1998, which conforms to European Union Regulation 86/609. Epididymal samples were collected from 185 Iberian red deer stags harvested in the game reserves of Ancares, Mampodre and Picos de Europa (León, Spain) and in several private hunting reserves of the province of Cáceres (Spain). All the animals were adult and lived in a free-ranging regime, and weighed 75.0 [67.5-108.5] kg. Harvest plans followed Spanish Harvest Regulation, Law 4/96 of Castilla y León and Law 19/01 of Extremadura, which conforms to European Union Regulation. Furthermore, species and number of individuals that can be hunted, as well as the exact periods of the year when hunting can take place, were reviewed each year by the Annual Hunting Regulation of the respective regions. 


\subsection{Electroejaculation procedure}

Stags were restrained and anesthetized with an intravenous injection of $0.75 \mathrm{mg} / \mathrm{kg}$ xilacine (Rompun ${ }^{\circledR} 2 \%$; Bayer AG, Leverkusen, Germany) and $1.5 \mathrm{mg} / \mathrm{kg}$ ketamine (Imalgene $1000^{\circledR}$; Rhone-Mérieux, Lyon, France). Before performing the electroejaculation, we recorded several morphological parameters: body weight using an electronic scale, and width of each testicle (axis parallel to the cephalocaudal axis) and thickness of the scrotal wall using a caliper. We estimated the testicular width by subtracting the thickness of the scrotal wall. Rectum was cleaned from faeces and the prepucial area was shaved and washed with physiological saline. Electroejaculation was carried out using a rectal probe measuring $375 \mathrm{~mm}$ length and $40 \mathrm{~mm}$ width; the length of the electrodes was $80 \mathrm{~mm}$. The probe was connected to a power source that allowed to controlling voltage and amperage. Ejaculation occurred at average values of $4.5 \mathrm{~V}$ and $90 \mathrm{~mA}$ (average time to ejaculation: $3 \mathrm{~min}$ $44 \mathrm{~s}$ ). Anesthesia was reverted with $0.3 \mathrm{mg} / \mathrm{kg}$ yohimbine hydrochloride (prepared at 0.9\%; Sigma, Madrid, Spain). Samples suspected of urine contamination (abnormal color and observations during the electroejaculation procedure) were discarded. We conducted 37 electroejaculations in the 18 farmed stags.

\subsection{Post-mortem sperm recovery}

The scrotum, including testicles and epididymes, was removed from the carcass and refrigerated at $5{ }^{\circ} \mathrm{C}$ as soon as possible. Date and time of death, collection and refrigeration were noted and attached to the corresponding sample. Refrigerated genitalia were sent to our laboratory at the Veterinary Clinic Hospital of the University of León (Spain). Sample manipulation was carried out in a walk-in fridge $\left(5{ }^{\circ} \mathrm{C}\right)$. Testicles with epididymes and vas deferens attached were isolated from the scrotum and other tissues. Epididymes were dissected free from the testicles, and cleaned of connective tissue. We recorded testicular weight and cauda epididymal weight by using an electronic scale, and the testicular width (axis parallel to the cephalocaudal axis) by using a caliper. Before starting sperm collection from the cauda epididymis, we pierced the superficial blood vessels, wiping out the blood. Spermatozoa were collected making several incisions on the cauda with a surgical blade, and taking the sperm mass emerging from the cut tubules with the aid of the blade. Sample from both epididymes of the same animal was mixed and weighed before further manipulation. We collected and processed the testicles of 179 stags.

Only 30 post-mortem samples could be processed between 18 and $26 \mathrm{~h}$ post-mortem, and these were used for sperm quality analyses $(\mathrm{pH}$, osmolality, motility, abnormal forms, viability). We considered this time as acceptable for maintaining sperm quality, based in previous studies in red deer $[17,28]$.

\subsection{Spermatozoa quality}

All chemicals were of at least Reagent grade, and were acquired from Sigma (Madrid, Spain). For fixing sperm samples, we used a $2 \%$ glutaraldehyde solution (146 mM glucose, $34 \mathrm{mM}$ sodium citrate tribasic and $24 \mathrm{mM} \mathrm{NaHCO}$ ).

Each sample was measured for osmolality and $\mathrm{pH}$, using a cryoscopic osmometer (Osmomat-030, Gonotec $^{\mathrm{TM}}$; Berlin), and an electronic pH-meter (CG 837, Schott ${ }^{\mathrm{TM}}$; Mainz), respectively. The sperm concentration (spermatozoa/mL) was calculated using a Bürker hemocytometer, after diluting $5 \mu \mathrm{L}$ of sample in $500 \mu \mathrm{L}$ of fixing solution. The total number of collected spermatozoa was calculated by multiplying its concentration by the sample volume. For epididymal samples, the volume was estimated from sample weight (density previously determined as $0.94 \mathrm{~g} / \mathrm{mL}$ ).

Aliquots were fixed $(5 \mu \mathrm{L}$ in $500 \mu \mathrm{L}$ of fixing solution) for studying abnormal forms and cytoplasmic droplets using phase contrast microscopy $(\times 400)$ and at least 100 cells per sample. Cytoplasmic droplets were classified as proximal or distal. Proximal droplets were considered abnormal in all cases. Distal droplet were considered abnormalities only in the case of ejaculated samples, since the distal droplet is a normal occurrence in the epididymal spermatozoon of ruminants [29]. Other abnormal forms observed were macro and microcephalic spermatozoa, pyriform heads, loose heads, midpiece reflex, segmental aplasia, broken tail or coiled tail. Since we did not observe any special association of the diverse abnormalities with each kind of sample, for simplicity we show only the total percentage.

\subsection{CASA and fluorescence-based analysis}

CASA (Computer Assisted Sperm Analysis) motility assessment was carried out as follow. The sample was diluted down to $20 \times 10^{6}$ spermatozoa/mL in PBS $(\mathrm{pH}$ $7.5,320 \mathrm{mOsm} / \mathrm{kg}$; for epididymal sperm we increased osmolality to $380 \mathrm{mOsm} / \mathrm{kg}$ with $\mathrm{NaCl}$, isoosmotic for this kind of samples). A $5 \mu \mathrm{L}$ drop was put on a slide at 
$37^{\circ} \mathrm{C}$, covered with a $22 \times 22$ coverslip and examined (5 fields at least) with a phase contrast microscope (Nikon Labophot-2; negative contrast optics) with a warming stage at $37{ }^{\circ} \mathrm{C}$. Analysis was carried out using the Motility Analyzer v. 7.4G (Hamilton-Thorne Research) and the following parameters were used for the study: total motility (\%; TM), progressive motility $(\% ; \mathrm{PM})$, curvilinear path velocity $(\mu \mathrm{m} / \mathrm{s}$; VCL), linearity (\%; LIN), amplitude of the lateral movement of the head $(\mu ;$ ALH) and beat cross frequency $(\mathrm{Hz} ; \mathrm{BCF})$. A spermatozoa was considered motile when VCL $>10 \mu \mathrm{m} / \mathrm{s}$, and progressive if VCL $>25 \mu \mathrm{m} / \mathrm{s}$ and STR $>80 \%$ (STR, Straightness, was also provided by the CASA). Explanation of the descriptors of sperm movement has been thoroughly reported [30]. We used the following configuration as displayed in the software setup: frames acquired: 20; frame rate: $25 / \mathrm{s}$; minimum contrast: 10 ; minimum size: 9; Lo/Hi size gates: 0.9/2.1; Lo/Hi intensity gates: $0.4 /$ 1.6; non-motile head size: 9; non-motile brightness: 10 ; medium VAP value: 25 ; low VAP value: 10; slow cells motile: NO; threshold STR: 80. Thus, the image acquisition rate was 25 frames/s and the acquisition time was $0.8 \mathrm{~s}$.

Sperm viability and acrosomal status were assessed using fluorescent probes (modified from Cheng et al. [31]). Samples were diluted 1:100 in PBS ( $\mathrm{pH} 7.5$, $320 \mathrm{mOsm} / \mathrm{kg} ; 380 \mathrm{mOsm} / \mathrm{kg}$ for epididymal samples), and stained with prodidium ioide (PI; $25 \mu \mathrm{g} / \mathrm{L}$ ) and PNA lectin conjugated with FITC $(1 \mu \mathrm{g} / \mathrm{mL})$. After $10 \mathrm{~min}$, the samples were analyzed with an epifluorescence microscope (Nikon Optiphot; $\times 400,450$ $490 \mathrm{~nm}$ excitation filter, $510 \mathrm{~nm}$ dichroic-beam splitter, $520 \mathrm{~nm}$ barrier filter). At least 100 cells were evaluated, discriminating between red (non-viable, acrosome intact), red-green (non-viable, acrosome damaged), green (viable, acrosome damaged) and non-stained (viable; acrosome intact) spermatozoa. For data analysis, we used the percentage of viable spermatozoa (PI-cells) and the percentage of spermatozoa with intact acrosome (PNA-cells).

\subsection{Statistical analysis}

Results are shown as median and interquartile range [25\% quartile-75\% quartile]. For the statistical analysis, we used the $R$ statistical environment [32]. We used linear models and regression analysis (Spearman's rank correlation) to study the effect of age and sample source (post-mortem or ejaculated) on the parameters analyzed. Due to the skew of the data, it was subjected to appropriate transformations (logarithmic or arc sine) in order to normalize it. Whenever the age was considered an unimportant factor, we used the asymptotic Wilcoxon Mann-Whitney rank-sum test for comparing electroejaculation and post-mortem samples. The data collected was very heterogeneous; thus, despite transforming it, we preferred using non-parametric tests in these comparisons.

A testicular production ratio was produced by dividing the number of spermatozoa obtained (from the epididymis or by elecroejaculation) by the corresponding testicular diameter (sum of right and left sides), and this parameter was compared between post-mortem (wild) and electroejaculation (farm) groups by using linear models. Moreover, following Malo et al. [33], we calculated a relative testicular size by summing the diameters of both testicles and dividing by the weight of the animal. We used linear models to study the association between testicular size (weight and diameter), epididymal weight and the relative testicular size with the concentration and total number of spermatozoa collected.

\section{Results}

\subsection{Testicular measurements}

In post-mortem samples, stag age was linearly related to testicular weight $\left(r^{2}=0.60\right)$ and epididymal weight $\left(r^{2}=0.53\right)$ (Fig. $\left.1 ; P<0.001\right)$. We did not find significant differences between testicular diameter obtained from the electroejaculation experiment and from the post-mortem experiment (Fig. 2), and it was also linearly related to stag age with $r^{2}=0.57$ $(P<0.001)$ The relative testicular size (ratio testicular diameter:body weight) was not constant throughout age, but adjusted to a negative exponential model in both groups of animals $(P<0.05)$, indicating that body weight and testicular growth followed different trends, with younger animals having faster body growth than testicular growth. The variation of the relative testicular size was similar in the farmed and wild groups $(P>0.05)$.

\subsection{Sperm data}

Sperm concentration (Fig. 3a) was significantly higher for epididymal samples $(P<0.001)$, with a pooled median value of $4.10[3.04-4.86] \times 10^{9} / \mathrm{mL}$, whereas for electroejaculation samples we obtained 0.44 [0.29$0.80] \times 10^{9} / \mathrm{mL}$. However, the total number of spermatozoa per sample (Fig. 3b) did not differ statistically between epididymal $\left(2.50 \quad[1.68-5.03] \times 10^{9}\right)$ and 
(a)

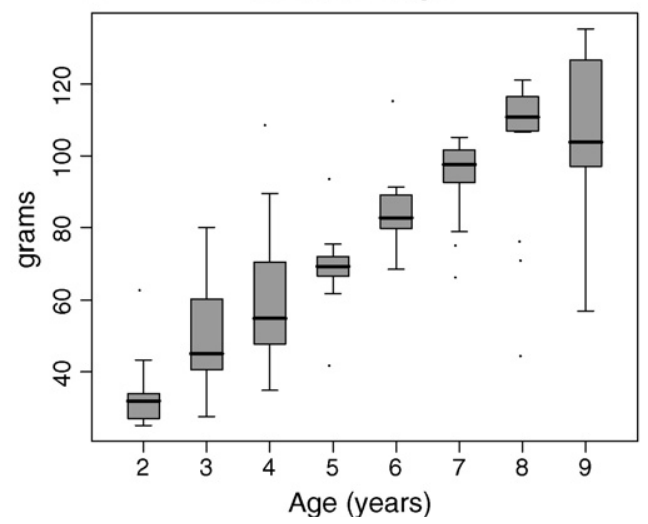

(b) Epididymal weight

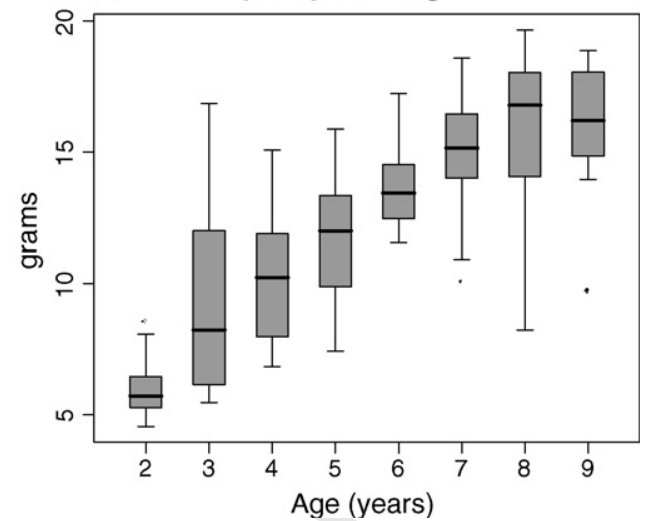

Fig. 1. Testicular weight (a) and epididymal weight (b) from the samples collected post-mortem, showing its variation with the estimated deer age. Testicular and epididymal data are averages of right and left sides. There was a linear relationship of both weights with age $\left(r^{2}=0.60\right.$ for testicular weight and $r^{2}=0.53$ for epididymal weight; $P<0.001$ ). The boxes spread from the $25 \%$ to the $75 \%$ quartiles, and the whiskers extend to $1.5 \times$ interquartile range. Observations beyond whisker limits are showed as dots. The median is indicated by a horizontal line.

electroejaculated samples $\left(3.60[1.74-5.55] \times 10^{9}\right)$. The testicular production ratio (spermatozoa collected/sum of testicular diameters) did not differed significantly between post-mortem (40.5 [23.9-55.7]) and ejaculation groups (34.5 [20.0-65.4]). In post-mortem samples, age was weakly related with sperm concentration $\left(r^{2}=0.07\right)$, total spermatozoa $\left(r^{2}=0.11\right)$ and testicular production ratio $\left(r^{2}=0.20\right)(P<0.001)$. In this group, testicular diameter was also weakly related with sperm concentration $\left(r^{2}=0.12\right)$ and total spermatozoa $\left(r^{2}=0.36\right)$ $(P<0.001)$, whereas testicular weight was related with total spermatozoa $\left(r^{2}=0.17 ; P<0.001\right)$, but not with

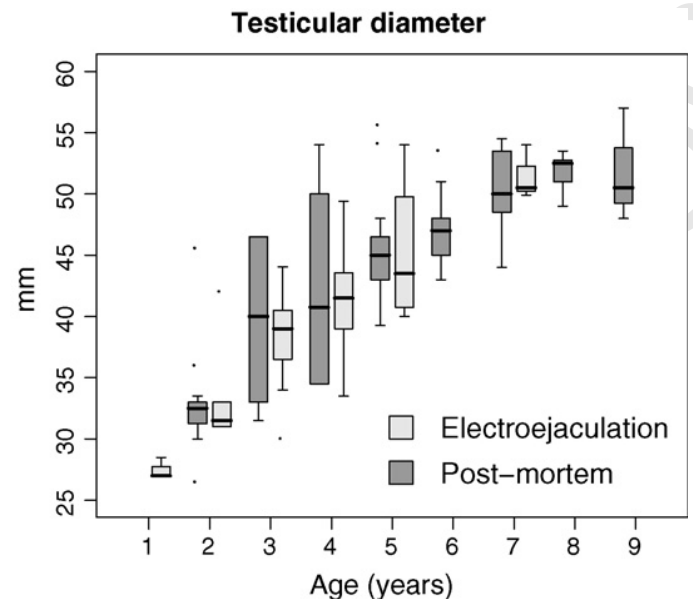

Fig. 2. Increase of testicular diameter (average of right and left sides) with increasing male age, for post-mortem samples and electroejaculated animals. There was a very significant linear relationship between both parameters $\left(r^{2}=0.69 ; P<0.001\right)$. The data from electroejaculated and post-mortem samples did not differ significantly. See Fig. 1 for a description of box plot elements. sperm concentration. Such relationships were not found in the electroejaculation group.

The $\mathrm{pH}$ and osmolality varied greatly between epididymal and electroejaculated samples (Fig. 3c and d). Ejaculated semen was more alkaline and had a lower osmolality than the samples collected from the cauda epididymis $(P<0.001)$. Pooled $\mathrm{pH}$ was 6.28 [6.19-6.52] for epididymal samples and 7.63 [7.16-8.10] for ejaculates. The $\mathrm{pH}$ of ejaculates also increased with age $\left(r^{2}=0.12, P=0.028\right)$, from 6.71 at 2 years of age to 8.19 at 7 years of age. We detected a sudden fall in $\mathrm{pH}$ measurements for 6-year-old stags; however, an analysis using linear mixed models (using deer and collection year as random effects) showed that this was rather an effect of collection year. Osmolality measurements yielded 378 [356-395] mOsm/kg for epididymal samples and 309 [321-332] $\mathrm{mOsm} / \mathrm{kg}$ for ejaculated semen.

Spermatozoa obtained by electroejaculation differed from those obtained from the cauda epididymis (Fig. 4). Although the percentage of motile spermatozoa was high and roughly similar for both kind of samples $(P=0.051)$, the quality of movement was much better for ejaculated samples. For instance, the median value of sperm velocity (VCL) and linearity (LIN) for ejaculated semen approximately doubled those of the epididymal samples $(112 \mu \mathrm{m} / \mathrm{s}$ and $81 \%$ vs. $53 \mu \mathrm{m} / \mathrm{s}$ and 44\%). The percentage of abnormal forms and proximal droplets was slightly larger for epididymal spermatozoa, although significant (abnormal forms: $29 \%$ vs. $18.8 \%$; proximal droplets: $3 \%$ vs. $0.6 \%$; $P<0.01$ ), but the difference in the percentage of spermatozoa bearing a distal cytoplasmic droplet was considerable ( $83 \%$ vs. $1.5 \% ; P<0.001)$. This is an 
(a) Sperm concentration

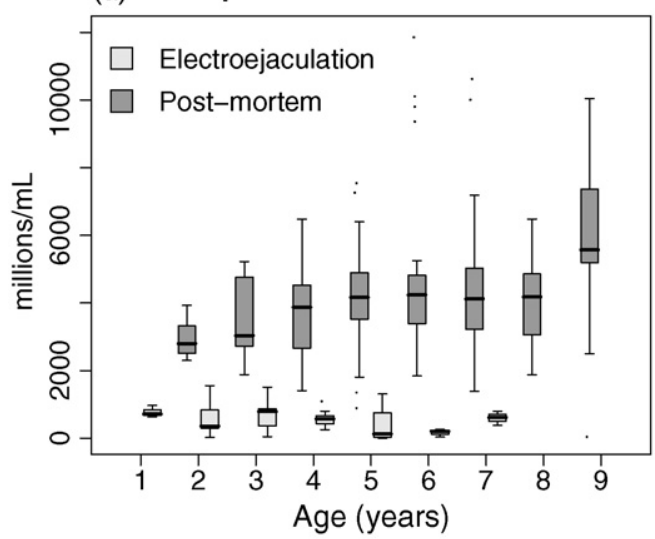

(c)

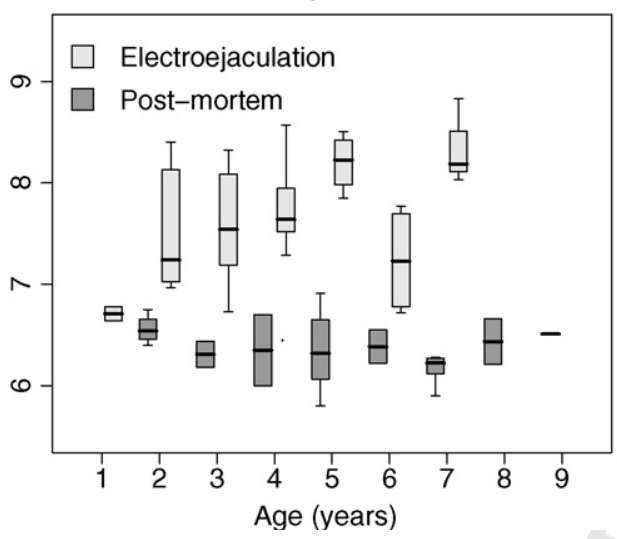

(b) Spermatozoa collected

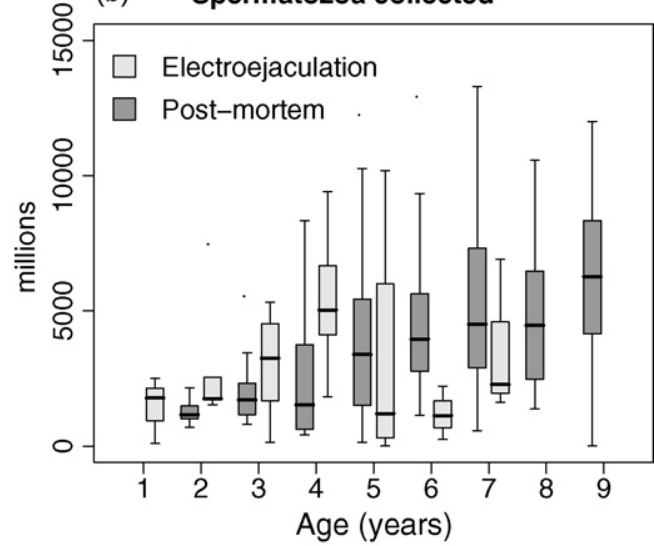

(d)

Osmolality

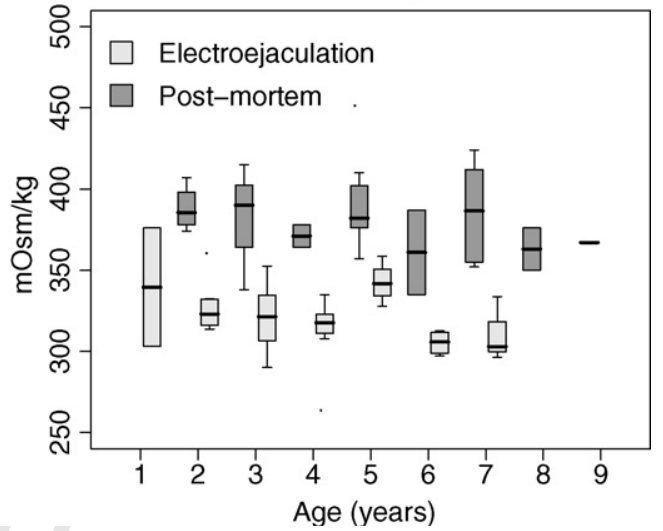

Fig. 3. Sperm concentration, total spermatozoa collected, $\mathrm{pH}$ and osmolality of electroejaculated and post-mortem samples, classified by age. Concentration, $\mathrm{pH}$ and osmolality were significantly different between post-mortem and ejaculated samples $(P<0.001)$. Age was significantly related to concentration and number of spermatozoa from post-mortem samples $(P<0.001)$, and to the $\mathrm{pH}$ of ejaculated semen $(P=0.028)$. See Fig. 1 for a description of box plot elements.

expected result when dealing with epididymal samples, since in ruminants the cytoplasmic droplet remains attached to the midpiece of the spermatozoa while in the epididymis, shedding when diluting in seminal plasma during the ejaculation [29]. The fluorescence probes PI and PNA-FITC indicated that the samples from both sources had a high percentage of membrane-intact (viable) and acrosome-intact spermatozoa. There were no significant differences between sources regarding viable spermatozoa (overall median: $74 \%$ ). Considering viable spermatozoa, ejaculated samples showed a higher proportion of intact acrosomes (97\% for ejaculate vs. $90 \%$ for epididymal sperm; $P=0.002$ ).

\section{Discussion}

In this study, we show novel data on Iberian red deer spermatology regarding two practical situations for sperm collection: post-mortem recovery from wild deer and electroejaculation of farmed stags. It could be argued that the environmental and rearing differences would affect the sperm characteristics in each group. Nevertheless, we have considered that in the practice each collection method is inseparable from the situation of the animals: post-mortem collection is the most convenient method for wild animals, especially when subjected to hunting programs, whereas electroejaculation is routinely used for farmed animals. Binding each collection method to the wild and farmed populations is not confounding, but indeed much more realistic that if both methods had been tested in the same population. It would be possible to perform a direct comparison of the post-mortem and electroejaculation methods, conducting electroejaculation and castration in the same animals, but this implies many difficulties. 

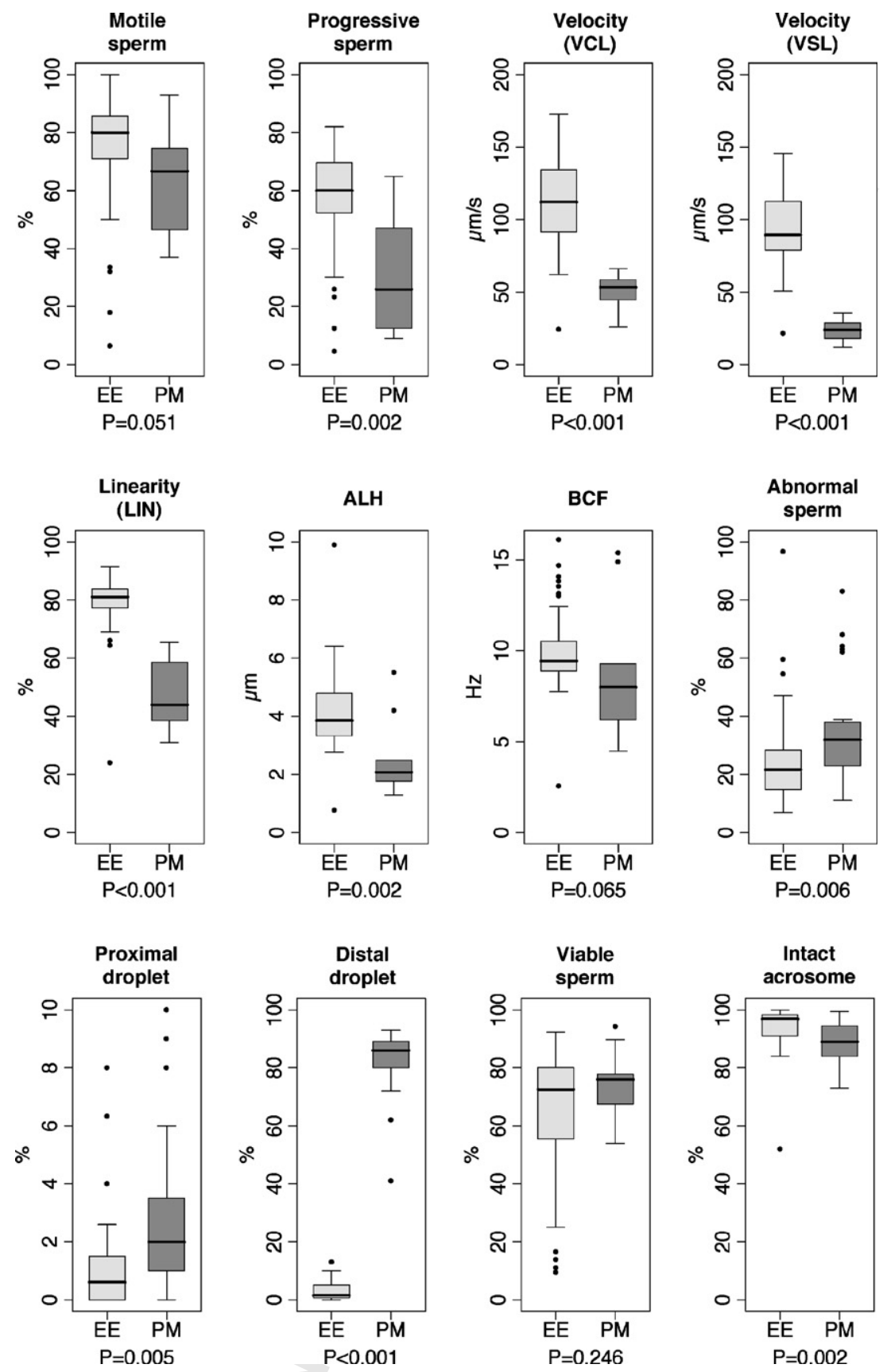

Fig. 4. Comparison of spermatozoa characteristics between electroejaculated samples (EE) and epididymal samples (PM). The $P$ values from the between-groups comparison are shown under each plot (asymptotic Wilcoxon Mann-Whitney rank-sum test). See Fig. 1 for a description of box plot elements. In the proximal droplets plot, a data point with value 54 (PM) was intentionally left out of the graph.

We have reported morphometric data regarding the testicular size of Iberian red deer. Although there are many differences with other subspecies (smaller size, adaptation to a dry environment, etc.) [10], our results might be generalizable. Few studies have considered the effect of age in testicular size of red deer. Lincoln [34] and Gomez et al. [35] worked only with young stags, aiming to study changes during and just after puberty. Lincoln [34] reported a testicular weight of $\sim 32$ and $\sim 40 \mathrm{~g}$ at 2 and 3 years of age, respectively. These weights are within the interquartile range reported in this study for these ages, even though Lincoln [34] worked with a different subspecies (possibly C. elaphus scoticus). Gomez et al. [35] used Iberian red deer, and 
reported a mean testicular diameter of $3 \mathrm{~cm}$ in yearlings and of $3.75 \mathrm{~cm}$ in 2-year old stags, which approximate our mean results for these ages $(3.1$ and $3.5 \mathrm{~cm}$, respectively). In our study, we have demonstrated for the age range 1-9 years a linear relationship between age and both testicular size and epididymal weight. The data obtained from 9-year-old deer (Figs. 1 and 2) suggest that testicular growth may slow down after 8 years of age, as showed in studies in bull [36] and buffalo [37,38]. This hypothesis should be tested in future studies including older animals. Moreover, the testicular and body growth rates were different. Body weight increased faster that testicular size in young males (1-3 year old), and then at a similar rate at older ages. This result differs from Malo et al. [33], who did not found any effect of age upon relative testicular size, although it is possible that most animals in that study were adult, thus presenting a constant relationship between both growth rates.

The increasing number of spermatozoa collected post-mortem in older animals could not be due only to the increase of testicular size, as showed by the low determination coefficients, but maybe by an improvement of spermatogenetic efficiency with age. Interestingly, a relationship between spermatozoa number and age was not found in electroejaculated samples. The reason might be that, whereas the collection technique allowed to recover most of the sperm reservoir in the cauda epididymis [39], the electroejaculation technique is bound to high variability in their results because of many factors (mainly due to the animal, such as stress, response to anesthesia, response to the stimulation, etc.). Although the yields of both techniques were not statistically different, we found a very high variability on the number of spermatozoa collected by electroejaculation. Unfortunately, we could not control for ancillary variables, because of restrictions imposed by animal rearing. From a practical point of view, spermatozoa yield was high enough to prepare a considerable number of insemination doses per sample. From the interquartile values and using $100 \times 10^{6}$ spermatozoa per dose [24], we could prepare 16-50 doses per epididymal sample or 17-55 doses per ejaculate. We obtained similar results in a previous study on epididymal spermatozoa [18], confirming post-mortem recovery as an adequate source of sperm doses in hunting areas. Gizejewski et al. [16] could collect $8.8 \pm 3.9 \times 10^{9}$ spermatozoa (mean \pm S.D.) from wild European red deers (C. elaphus carpaticus var. montanus) in the rut. The difference may rest in the larger size of these stags compared with the Iberian subspecies. In fact, the testicular weight reported by these authors was $155.9 \pm 26.8 \mathrm{~g}$ (mean \pm S.D.) for a median age of 9 years, much larger than the weights reported by us (mean weight at 9 years: $106.1 \mathrm{~g}$ ). However, in general, our results seem to be higher than those obtained by other authors. Thus, Malo et al. [40] (C. elaphus hispanicus) and Hishinuma et al. [41] (C. nippon) using a similar method for recovering epididymal spermatozoa, accounted for $1.9 \pm 0.1$ $\times 10^{9}$ and $1.3 \pm 0.5 \times 10^{9}$ (mean \pm S.E.M.) spermatozoa, respectively, whereas we were able to collect $3.9 \pm 0.2 \times 10^{9}$ spermatozoa per sample. The difference with the study of Malo et al. [40] can be explained by the fact that it was carried out after the rut (OctoberDecember), when epididymal sperm concentration is lower (previously showed in [18]). Regarding electroejaculation, Umapathy et al. [42] (Axis axis) and Monfort et al. [43] (C. eldi thamin) obtained in average less than $2.0 \times 10^{9}$ spermatozoa per ejaculate, whereas we obtained a mean value of $3.4 \times 10^{9}$ spermatozoa. In contrast, Mulley et al. [44] and Asher et al. [45] reported collecting more than $4.0 \times 10^{9}$ spermatozoa from Dama dama. A possible cause for these differences might be the lack of standardized protocols among studies.

In this study, we have showed that epididymal present higher concentration, have a lower $\mathrm{pH}$ and higher osmolality than ejaculated semen. FernandezSantos et al. [46] and Martinez-Pastor et al. [23] found that epididymal spermatozoa from Iberian red deer should be frozen in media of higher osmolality, more similar to epididymal fluid, rather than in the conventional one, isoosmotic to ejaculated spermatozoa. Moreover, we have found that electroejaculates increased their $\mathrm{pH}$ values with age. The explanation of this fact is beyond the scope of the present study, although we hypothesize that it might be due to changes in the secretions contributing to the seminal plasma. The ramifications of such a study would be many, since it could be aimed not only to identify the nature and the cause of this change of $\mathrm{pH}$, but also the physiological source and why it was related to age.

We did not find any significant effect of age in the sperm quality parameters. However, Garde et al. [11] reported that epididymal samples from young stags (2 and 3 years of age) had lower motility, more abnormal spermatozoa and less reactivity to the HOS test than older males. These authors proposed that, since the samples had been collected at the very beginning of the breeding season, these young animals had not reached the testosterone peak yet $[34,47]$, thus the worse results regarding sperm quality. It is possible that, in our study, most of the young stags were in the same conditions that 
the older males, not presenting prominent differences in their semen quality. Considering motility, although epididymal and ejaculated spermatozoa were similar regarding the percentage of motile and viable spermatozoa, CASA parameters (velocity, linearity, etc.) were lower for epididymal samples. We have to point out that these differences were not due to the different ability of the CASA system to deal with different kind of samples (analyses were confirmed by using the "replay" option of the software and by visual observation). Studies using CASA to analyze red deer motility are scarce, and only Malo et al. [40] showed CASA parameters in their study, which were higher than the ones showed here. There are two possible reasons for this difference: that study was carried out after the rut, when motility parameters are higher [18,27]; and the samples could be analyzed shortly after the death of the males. In our case, samples could not be processed immediately, and were transported refrigerated to lengthen their viability, which might have depressed their motility. We cannot forget that refrigerated storage of the testicles is very common when collecting samples from wild animals and the processing facilities are beyond several hours from the collection site, and therefore our results should rather be used as a reference for these situations. Nevertheless, it has observed previously that deer epididymal spermatozoa seemed to improve their motility once extended, suggesting that motility depression observed in freshly collected samples might often be temporal $[39,48,49]$. Moreover, MartinezPastor et al. [23], comparing many freezing protocols, found similar motility for both electroejaculated and epididymal samples after thawing, even though the epididymal spermatozoa had undergo refrigerated storage for about $20 \mathrm{~h}$. Furthermore, Soler and Garde [50] found a lack of correlation between classical parameters and penetration scores, motility among them, for red deer epididymal spermatozoa. Thus, it is possible that sperm motility of epididymal spermatozoa do not reflect its real ability on fertilization or cryopreservation when measured just after collection.

In conclusion, in this study we have demonstrated that stag age affects testicular and epididymal size and several sperm parameters, both in electroejaculated and post-mortem samples, but it does not seem to influence sperm quality. We also found that the growth rates of body weight and testicular size differed. Furthermore, we have presented data regarding many reproductive parameters of Iberian red deer, which may be of application on other subspecies and even in other cervid species, and have showed that it is possible to obtain a large number of spermatozoa by both electroejaculation or post-mortem collection. Moreover, we want to highlight that, despite the differences reported here and in previous studies, both electroejaculated and epididymal spermatozoa (considering quantity and quality) should be equally valid for establishing germplasm banks, either for conservation or selection. We expect that this study would help to improve the development of assisted reproductive techniques on this species, mainly regarding sperm collection, its manipulation and its cryopreservation. In this regard, the development of new cryopreservation protocols should take into account the differences between epididymal and electroejaculated spermatozoa, since they may behave differently depending on extender composition, freezing/thawing rates and other variables.

\section{Acknowledgements}

This study has been supported in part by Junta de Castilla y León (AB29) and Junta de Castilla-La Mancha (PREG-01-0006). The authors thank Juan José Martínez, César Gómez, Juan Carlos Peral, the Territorial Service of Environmental Affairs of León, and the gamekeepers of the hunting reserves of Picos de Europa, Mampodre and Ancares (León, Spain), and Carlos Bernabé (Cáceres, Spain) for their collaboration in the collection of the post-mortem samples; Camino Guerra and Patri Martínez for their help in the collection and processing of the samples and Jana Bernardo for helping in the preparation of the manuscript.

\section{References}

[1] Jabbour H, Hayssen V, Bruford M. Conservation of deer: contributions from molecular biology, evolutionary ecology, and reproductive physiology. J Zool 1997;243:461-84.

[2] Cseh S, Solti L. Importance of assisted reproductive technologies in the conservation of wild, rare or indigenous ungulates: review article. Acta Vet Hung 2000;48:313-23.

[3] Pukazhenthi BS, Wildt DE. Which reproductive technologies are most relevant to studying, managing and conserving wildlife? Reprod Fertil Dev 2004;16:33-46.

[4] Andrabi SMH, Maxwell WMC. A review on reproductive biotechnologies for conservation of endangered mammalian species. Anim Reprod Sci 2007;99:223-43.

[5] Gordon I. Controlled reproduction in deer. Controlled reproduc- Q4 tion in horses, deer and camelids, vol. 4 of controlled reproduction in farm animals. 1st ed. Oxon, UK: CAB International, p. $168-188$.

[6] Asher G, Berg D, Evans G, Salamon S, Maxwell W. Storage of semen and artificial insemination in deer. Anim Reprod Sci 2000;62:195-211.

[7] Fletcher TJ. Farmed deer: new domestic animals defined by controlled breeding. Reprod Fertil Dev 2001;13:511-6. 
[8] Asher GW, Monfort SL, Wemmer C. Comparative reproductive function in cervids: implications for management of farm and zoo populations. J Reprod Fertil Suppl 1999;54:143-56.

[9] Long C, Walker S, Tang R, Westhusin M. New commercial opportunities for advanced reproductive technologies in horses, wildlife, and companion animals. Theriogenology 2003;59:13949.

[10] Garde J, Martinez-Pastor F, Gomendio M, Malo A, Soler A, Fernandez-Santos M, et al. The application of reproductive technologies to natural populations of red deer. Reprod Domest Anim 2006;41(Suppl. 2):93-102.

[11] Garde J, Ortiz N, Garcia A, Gallego L, Landete CT, Lopez A. Postmortem assessment of sperm characteristics of the red deer during the breeding season. Arch Androl 1998;41:195-202.

[12] Bierschwal C, Mather E, Martin C, Murphy D, Korschgen L. Some characteristics of deer semen collected by electroejaculation. J Am Vet Med Assoc 1970;157:627-32.

[13] Jaczewski Z, Jasiorowski T. Observations on the electroejaculation in red deer. Acta Theriol (Warsz) 1974;19:151-7.

[14] Strzezek J, Krzywinski A, Swidowicz K. Seasonal changes in the chemical composition of red deer (Cervus elaphus) semen. Anim Reprod Sci 1985;9:195-204.

[15] Gizejewski Z. Effect of season on characteristics of red deer (Cervus elaphus 1.) semen collected using modified artificial vagina. Reprod Biol 2004;4:51-66.

[16] Gizejewski Z, Soderquist L, Rodriguez-Martinez H. Post-mortem examination of genital organs and characteristics of epididymal spermatozoa from wild red deer stags Cervus elaphus carpaticus var. montanus. In: Second World Conference; 1998.p. $121-8$.

[17] Martinez-Pastor F, Guerra C, Kaabi M, Diaz AR, Anel E, Herraez P, et al. Decay of sperm obtained from epididymes of wild ruminants depending on postmortem time. Theriogenology 2005;63:24-40.

[18] Martinez-Pastor F, Guerra C, Kaabi M, Garcia-Macias V, de Paz $\mathrm{P}$, Alvarez M, et al. Season effect on genitalia and epididymal sperm from Iberian red deer, roe deer and Cantabrian chamois. Theriogenology 2005;63:1857-75.

[19] Gomendio M, Malo AF, Soler AJ, Fernandez-Santos MR, Esteso MC, Garcia AJ, et al. Male fertility and sex ratio at birth in red deer. Science 2006;314:1445-7.

[20] Comizzoli P, Mermillod P, Cognie Y, Chai N, Legendre X, Mauge R. Successful in vitro production of embryos in the red deer (Cervus elaphus) and the sika deer (Cervus nippon). Theriogenology 2001;55:649-59.

[21] Fernández-Santos M, Esteso M, Soler A, Montoro V, Garde J. Effects of egg yolk and cooling rate on the survival of refrigerated red deer (Cervus elaphus hispanicus) epididymal spermatozoa. Reprod Domest Anim 2006;41:114-8.

[22] Fernandez-Santos M, Esteso M, Montoro V, Soler A, Garde J. Cryopreservation of Iberian red deer (Cervus elaphus hispanicus) epididymal spermatozoa: effects of egg yolk, glycerol and cooling rate. Theriogenology 2006;66:1931-42.

[23] Martinez-Pastor F, Martinez F, Garcia-Macias V, Esteso M, Anel E, Fernandez-Santos M, et al. A pilot study on post-thawing quality of Iberian red deer spermatozoa (epididymal and electroejaculated) depending on glycerol concentration and extender osmolality. Theriogenology 2006;66:1165-72.

[24] Soler AJ, Garcia AJ, Fernandez-Santos MR, Esteso MC, Garde JJ. Effects of thawing procedure on postthawed in vitro viability and in vivo fertility of red deer epididymal spermatozoa cryopreserved at $-196^{\circ} \mathrm{C}$. J Androl 2003;24:746-56.
[25] Zomborszky Z, Nagy S, Nánássy L, Szabari M, Bodó S. Experiences in deer sperm cryopreservation under practical conditions-a pilot study. Anim Reprod Sci 2005;90: 185-90.

[26] Zomborszky Z, Zubor T, Toth J, Horn P. Sperm collection from shot red deer stags (Cervus elaphus) and the utilisation of sperm frozen and subsequently thawed. Acta Vet Hung 1999;47:26370.

[27] Martinez-Pastor F, Diaz-Corujo A, Anel E, Herraez P, Anel L, de Paz P. Post mortem time and season alter subpopulation characteristics of Iberian red deer epididymal sperm. Theriogenology 2005;64:958-74.

[28] Soler AJ, Perez-Guzman MD, Garde JJ. Storage of red deer epididymides for four days at $5{ }^{\circ} \mathrm{C}$ : effects on sperm motility, viability, and morphological integrity. J Exp Zoolog Part A Comp Exp Biol 2003;295:188-99.

[29] Cooper TG. Cytoplasmic droplets: the good, the bad or just confusing? Hum Reprod 2005;20:9-11.

[30] Boyers SP, Davis R, Katz D. Automated semen analysis. Curr Probl Obstet Gynecol Fertil 1989;12:172-200.

[31] Cheng F, Fazeli A, Voorhout W, Marks A, Bevers M, Colenbrander B. Use of peanut agglutinin to assess the acrosomal status and the zona pellucida-induced acrosome reaction in stallion spermatozoa. J Androl 1996;17:674-82.

[32] R Development Core Team. R: a language and environment for statistical computing. Vienna, Austria: R Foundation for Statistical Computing; 2007.

[33] Malo A, Roldan E, Garde J, Soler A, Gomendio M. Antlers honestly advertise sperm production and quality. Proc Biol Sci 2005;272:149-57.

[34] Lincoln GA. Puberty in a seasonally breeding male, the red deer stag (Cervus elaphus 1.). J Reprod Fertil 1971;25:41-54.

[35] Gomez JA, Garcia AJ, Landete-Castillejos T, Gallego L. Effect of advancing births on testosterone until 2.5 years of age and puberty in Iberian red deer (Cervus elaphus hispanicus). Anim Reprod Sci 2006;96:79-88.

[36] Coulter GH, Foote RH. Relationship of testicular weight to age and scrotal circumference of Holstein bulls. J Dairy Sci 1976;59:730-2.

[37] McCool CJ, Entwistle KW. Reproductive function in the Australian Swamp buffalo bull: age effects and seasonal effects. Theriogenology 1989;31:583-94.

[38] Pant HC, Sharma RK, Patel SH, Shukla HR, Mittal AK, Kasiraj $\mathrm{R}$, et al. Testicular development and its relationship to semen production in Murrah buffalo bulls. Theriogenology 2003;60 :27-34.

[39] Martinez-Pastor F, Garcia-Macias V, Alvarez M, Chamorro C, Herraez P, de Paz P, et al. Comparison of two methods for obtaining spermatozoa from the cauda epididymis of Iberian red deer. Theriogenology 2006;65:471-85.

[40] Malo A, Garde J, Soler A, García A, Gomendio M, Roldan E. Male fertility in natural populations of red deer is determined by sperm velocity and the proportion of normal spermatozoa. Biol Reprod 2005;72:822-9.

[41] Hishinuma M, Suzuki K, Sekine J. Recovery and cryopreservation of sika deer (Cervus nippon) spermatozoa from epididymides stored at $4{ }^{\circ} \mathrm{C}$. Theriogenology 2003;59:813-20.

[42] Umapathy G, Sontakke SD, Reddy A, Shivaji S. Seasonal variations in semen characteristics, semen cryopreservation, estrus synchronization, and successful artificial insemination in the spotted deer (Axis axis). Theriogenology 2007;67 :1371-8. 
[43] Monfort S, Brown J, Bush M, Wood T, Wemmer C, Vargas A, et al. Circannual inter-relationships among reproductive hormones, gross morphometry, behaviour, ejaculate characteristics and testicular histology in Eld's deer stags (Cervus eldi thamin). J Reprod Fertil 1993;98:471-80.

[44] Mulley R, Moore N, English A. Successful uterine insemination of fallow deer with fresh and frozen semen. Theriogenology 1988;29:1149-53.

[45] Asher G, Fisher M, Fennessy P, Mackintosh C, Jabbour H, Morrow C. Oestrous synchronization, semen collection and artificial insemination of farmed red deer (Cervus elaphus) and fallow deer (Dama dama). Anim Reprod Sci 1993;33 $: 241-65$.

[46] Fernandez-Santos MR, Martinez-Pastor F, Garcia-Macias V, Esteso MC, Soler AJ, de Paz P, et al. Extender osmolality and sugar supplementation exert a complex effect on the cryopreservation of Iberian red deer (Cervus elaphus hispani- cus) epididymal spermatozoa. Theriogenology 2007;67: 738-53.

[47] Haigh JC, Cates WF, Glover GJ, Rawlings NC. Relationships between seasonal changes in serum testosterone concentrations, scrotal circumference and sperm morphology of male wapiti (Cervus elaphus). J Reprod Fertil 1984;70:413-8.

[48] Martinez-Pastor F, Garcia-Macias V, Alvarez M, Herraez P, Anel L, de Paz P. Sperm subpopulations in Iberian red deer epididymal sperm and their changes through the cryopreservation process. Biol Reprod 2005;72:316-27.

[49] Martinez-Pastor F, Anel L, Guerra C, Alvarez M, Soler AJ, Garde JJ, et al. Seminal plasma improves cryopreservation of Iberian red deer epididymal sperm. Theriogenology 2006;66:1847-56.

[50] Soler AJ, Garde JJ. Relationship between the characteristics of epididymal red deer spermatozoa and penetrability into zonafree hamster ova. J Androl 2003;24:393-400. 